\title{
Redox Control of Resistance to cis-Diamminedichloroplatinum (II) (CDDP) Protective Effect of Human Thioredoxin against CDDP-induced Cytotoxicity
}

\author{
Tetsuro Sasada, ${ }^{\star}$ Satoshi Iwata, ${ }^{*}$ Norihito Sato, ${ }^{*}$ Yuki Kitaoka, ${ }^{*}$ Kiichi Hirota, ${ }^{\star}$ Kazuhiro Nakamura, ${ }^{*}$ Akira Nishiyama, \\ Yoshihisa Taniguchi, ${ }^{*}$ Arimichi Takabayashi, ${ }^{\ddagger}$ and Junji Yodoi ${ }^{*}$ \\ *Department of Biological Responses, Institute for Virus Research, Kyoto University, Kyoto 606-01, Japan; and ${ }^{\ddagger}$ Department of Surgery, \\ Tazuke Kofukai Kitano Hospital Medical Institute, Osaka 530, Japan
}

\begin{abstract}
Thioredoxin is a small ubiquitous protein with multiple biological functions, including cellular defense mechanisms against oxidative stress. In the present study, we investigated the role of human thioredoxin (hTRX) in the acquisition of cellular resistance to cis-diamminedichloroplatinum (II) (CDDP). The expression and activity of hTRX in Jurkat $T$ cells was dose-dependently enhanced by exposure to CDDP, as determined by immunoblot analysis and insulin reducing assay. Furthermore, chloramphenicol acetyltransferase analysis using the hTRX promoter-reporter gene construct revealed that treatment of Jurkat cells with CDDP caused transcriptional activation of the hTRX gene, which might be mediated through increased generation of intracellular reactive oxygen intermediates. To examine the biological significance of hTRX induction, we established hTRXoverexpressing derivatives of L929 fibrosarcoma cells by stable transfection with the hTRX cDNA. The clones, which constitutively expressed the exogenous hTRX, displayed increased resistance to CDDP-induced cytotoxicity, compared with the control clones. After exposure to CDDP, the control cells showed a significant increase in the intracellular accumulation of peroxides, whereas the hTRX-transfected cells did not. Taken together, these results suggest that overexpressed hTRX is responsible for the development of cellular resistance to CDDP, possibly by scavenging intracellular toxic oxidants generated by this anticancer agent. (J. Clin. Invest. 1996. 97:2268-2276.) Key words: human thioredoxin • cis-diamminedichloroplatinum (II) • resistance $\cdot$ reactive oxygen intermediate $\bullet$ redox
\end{abstract}

\section{Introduction}

Thioredoxin (TRX) $)^{1}$ is a small multifunctional and ubiquitous protein having a redox-active disulfide/dithiol within the conserved active site sequence: -Cys-Gly-Pro-Cys- $(1,2)$. Since its original isolation from Escherichia coli as a hydrogen donor for ribonucleotide reductase, the key enzyme in the biosynthesis of deoxyribonucleotides, TRX has been purified and char-

Address correspondence to Junji Yodoi, Department of Biological Responses, Institute for Virus Research, Kyoto University, 53 Kawahara-cho, Shogoin, Sakyo-ku, Kyoto 606-01, Japan. Phone: 81-75-7514024; FAX: 81-75-761-5766; E-mail: yodoi@virus.kyoto_u.ac.jp

Received for publication 1 September 1995 and accepted in revised form 22 February 1996.

J. Clin. Invest.

(C) The American Society for Clinical Investigation, Inc. 0021-9738/96/05/2268/09 \$2.00

Volume 97, Number 10, May 1996, 2268-2276 acterized from a wide variety of prokaryotic and eukaryotic species $(1,2)$. Adult $\mathrm{T}$ cell leukemia-derived factor (ADF), which we originally defined as an IL-2 receptor $\alpha$-chain/Tac inducer produced by human $\mathrm{T}$ cell lymphotropic virus-I-transformed $\mathrm{T}$ cells, has been identified as human thioredoxin (hTRX) (3-6). It has been suggested that hTRX has multiple biological functions and regulates different systems via thiol redox control, including the reduction of oxidized ribonucleotide reductase, the degradation of insulin, and the redox regulation of transcription factors $(1,2,5,7,8)$. hTRX has also been shown to be a scavenger of reactive oxygen intermediates (ROI) (9), and recombinant hTRX (rTRX) has a protective activity against hydrogen peroxide $\left(\mathrm{H}_{2} \mathrm{O}_{2}\right)$ - or TNF $\alpha$-induced cytotoxicity, in which the generation of ROI seems to be involved $(10,11)$. Furthermore, hTRX has been reported to be a stress-inducible protein, whose expression is enhanced by a variety of oxidative stresses, including $\mathrm{H}_{2} \mathrm{O}_{2}$, x-ray, and ultraviolet exposure $(5,11,12)$. These observations suggest that hTRX has an important role in the cellular responses against oxidative stress.

The tendency of tumors to express resistance to anticancer chemotherapeutic drugs has been a significant obstacle against successful treatment of cancer. cis-Diamminedichloroplatinum (II) (CDDP) is one of the most effective chemotherapeutic drugs for a variety of human malignancies, including ovarian, testicular, bladder, head and neck, esophageal, and small-cell lung cancers, and the development of resistance to this drug has restricted the efficacy of cancer treatment. Thus, it is particularly important to elucidate the mechanisms by which resistance to CDDP ocurrs and to develop a clinically useful means of overcoming the CDDP resistance in human cancer cells. Previous studies have suggested that cellular sensitivity against CDDP-induced cytotoxicity is modulated by several mechanisms, including accumulation of CDDP, DNA-repair processes, and inactivating factors, such as glutathione and metallothioneins $(13,14)$. In addition, several investigators have reported that administration of free radical scavengers or antioxidants, such as SOD or $\alpha$-tocopherol, inhibits the CDDPinduced nephrotoxicity in in vivo animal models (15-17). Indeed, increased generation of ROI seems to be closely associated with CDDP-induced cytotoxicity (15-19).

hTRX has been shown to be highly expressed in a variety of human malignant cells, including adult $\mathrm{T}$ cell leukemia caused by human $\mathrm{T}$ cell lymphotropic virus-I, squamous cell

1. Abbreviations used in this paper: $\mathrm{ADF}$, adult $\mathrm{T}$ cell leukemiaderived factor; BHA, butylated hydroxyanisole; CAT, chloramphenicol acetyltransferase; CDDP, cis-diamminedichloroplatinum (II); DCFH, 2', 7'-dichlorofluorescin; DCFH-DA, 2',7'-dichlorofluorescin diacetate; hTRX, human TRX; MTT, 3-(4,5-dimethylthiazol2-yl)-2,5-diphenyltetrazorium bromide; ROI, reactive oxygen intermediates; rTRX, recombinant hTRX; TRX, thioredoxin. 
carcinoma of the uterine cervix, hepatocellular carcinoma, lung carcinoma, and adenocarcinoma of the gastrointestinal tract $(6,20-22)$. In addition, it has been recently recognized that some CDDP-resistant human cancer cell lines have higher levels of hTRX expression $(23,24)$. Therefore, we have hypothesized that hTRX, which can function as an endogenous cellular redox buffer through its ROI-scavenging activity, may be an attractive candidate as a modulator of cellular sensitivity against CDDP. In the present study, we examined the role of hTRX in the acquisition of cellular resistance to CDDPinduced cytotoxicity. We report here that CDDP induces transcriptional activation of the hTRX gene, and that the hTRXoverexpressing cells display increased resistance to CDDP. Our findings strongly suggest that overexpressed hTRX induced by CDDP-mediated oxidative stress acts as an inhibitor of CDDP-induced cytotoxicity.

\section{Methods}

Reagents. CDDP, butylated hydroxyanisole (BHA), NADPH, insulin, and 3-(4,5-dimethylthiazol-2-yl)-2,5-diphenyltetrazorium bromide (MTT) were obtained from Sigma Chemical Co. (St. Louis, MO). RPMI 1640, FCS, and G418 were from Life Technologies Inc. (Grand Island, NY). DME was supplied from Nissui Pharmaceutical Co. (Tokyo, Japan). 2',7'-dichlorofluorescin diacetate (DCFH-DA) was from Molecular Probes, Inc. (Eugene, OR). rTRX was produced and provided by Ajinomoto Co. Inc., Basic Research Laboratory (Kawasaki, Japan), according to the method described previously (9). Anti-hTRX mAb (ADF-11 mAb; mouse IgG1), established by immunizing BALB/c mice with rTRX, was provided by Fujirebio Inc. (Tokyo, Japan). This mAb can specifically recognize hTRX, but not mouse TRX, determined by immunoblot analysis with recombinant human and mouse TRX (Sasada, T., K. Hirota, and J. Yodoi, unpublished observations). Human TRX reductase was purified from termdelivery human placenta and its activity (units per milliliter) was determined by insulin reducing assay as described (25). All other reagents were purchased from Nacalai Tesque Inc. (Kyoto, Japan) unless otherwise stated.

Cell culture. Jurkat, a human $\mathrm{T}$ cell line, was maintained in RPMI 1640 medium supplemented with $10 \%$ FCS and antibiotics (100 U/ml penicillin and $100 \mu \mathrm{g} / \mathrm{ml}$ streptomycin), in a humidified atmosphere of $5 \% \mathrm{CO}_{2} / 95 \%$ air at $37^{\circ} \mathrm{C}$. $\mathrm{L} 929$, a murine fibrosarcoma cell line, and its transfected derivatives were cultured in DME supplemented with $10 \%$ FCS and antibiotics $(100 \mathrm{U} / \mathrm{ml}$ penicillin and 100 $\mu \mathrm{g} / \mathrm{ml}$ streptomycin) in a humidified atmosphere of $5 \% \mathrm{CO}_{2} / 95 \%$ air at $37^{\circ} \mathrm{C}$. The transfected derivatives of L929 cells were continuously maintained in the presence of $200 \mu \mathrm{g} / \mathrm{ml} \mathrm{G} 418$.

Immunoblot analysis for hTRX protein. The expression of hTRX protein was determined by immunoblot analysis using anti-hTRX $\mathrm{mAb}$ (ADF-11 mAb). Cells were washed with ice-cold PBS three times, and then lysed with a solubilizing solution $(0.5 \%$ NP- 40,10 $\mathrm{mM}$ Tris- $\mathrm{HCl}$ ( $\mathrm{pH} 7.2), 150 \mathrm{mM} \mathrm{NaCl}, 1 \mathrm{mM}$ PMSF, $0.111 \mathrm{U} / \mathrm{ml}$ aprotinin, and $0.02 \% \mathrm{NaN}_{3}$ ) on ice for $30 \mathrm{~min}$. The extracts were cleared by centrifugation. Equal amounts of protein ( 5 or $10 \mu \mathrm{g}$ protein/lane), estimated by the Bradford method using a protein assay (Bio-Rad Laboratories, Hercules, CA), were subjected to electrophoresis on a $15 \%$ SDS-polyacrylamide gel, and then electrophoretically transferred to a polyvinylidene difluoride membrane (Millipore Corp., Bedford, MA). After blocking with $10 \%$ FCS and $10 \%$ skim milk in PBS containing $0.05 \%$ Tween 20 at $4^{\circ} \mathrm{C}$ overnight, the membrane was incubated with anti-hTRX mAb (ADF-11 mAb), followed by peroxidase-linked anti-mouse Ig (Amersham Intl., Little Chalfont, UK). Detection by chemiluminescence was performed with an ECL Western blot detection kit (Amersham Intl.) according to the supplier's recommendation.
Determination of TRX and TRX reductase activity. The activity of TRX and TRX reductase in cells was determined by insulin reducing assay, according to the method previously described by Holmgren and co-workers, with slight modification $(26,27)$. Mammalian TRX reductase has been reported to have a broad substrate specificity and reduce TRXs from different species $(26,28)$, and we have also found that human TRX reductase can react with recombinant mouse TRX as efficiently as recombinant human TRX (Sasada, T., K. Hirota, and J. Yodoi, unpublished observations). Cells were washed with ice-cold PBS three times, and then homogenized by repeated freezing and thawing. The protein concentration of cell extracts was measured by the Bradford method. For determination of the TRX activity, equal amounts of total cellular protein $(20 \mu \mathrm{g}$ for the parental and transfected L929 cells or $40 \mu \mathrm{g}$ for Jurkat cells) in a volume of $8 \mu \mathrm{l}$ were preincubated with $2 \mu \mathrm{l}$ of the DTT activation buffer $(0.1 \mathrm{M}$ Tris-Cl (pH 7.5), $2 \mathrm{mM}$ EDTA containing $1 \mathrm{mg} / \mathrm{ml} \mathrm{BSA}$ and $2 \mathrm{mM}$ DTT) at $37^{\circ} \mathrm{C}$ for $15 \mathrm{~min}$, to reduce and activate TRX, which might contain aggregated material with inter- or intramolecular disulfides (27). The preincubated cell extracts were mixed with $110 \mu$ l of the reaction mixture (0.1 M Tris-Cl (pH 7.5), 2 mM EDTA, 0.2 mM NADPH, 0.4 $\mathrm{U} / \mathrm{ml}$ human TRX reductase, $140 \mu \mathrm{M}$ insulin) and incubated at $25^{\circ} \mathrm{C}$. The reaction was followed by recording the decrease in absorbance at $340 \mathrm{~nm}$, which reflected the oxidation of NADPH, at 30-s intervals. As a control for other oxidoreductases consuming NADPH in the crude cell extracts, the preincubated extracts were mixed with the reaction mixture containing everything except insulin and treated the same way as all other samples. From the change in absorbance of each sample was subtracted the change in absorbance of the respective control sample lacking insulin. The calculated values were compared to the standard curve for rTRX (100-1,200 $\mathrm{ng} / \mathrm{ml})$ to obtain quantitative determinations of the absolute amounts of TRX. For determination of the TRX reductase activity, equal amounts of total cellular protein $(5 \mu \mathrm{g}$ for the parental and transfected L929 cells) in a volume of $10 \mu \mathrm{l}$ were mixed with $110 \mu \mathrm{l}$ of the reaction mixture (0.1 M Tris-Cl (pH 7.5), $2 \mathrm{mM}$ EDTA, $0.2 \mathrm{mM}$ NADPH, $10 \mu \mathrm{M}$ rTRX, and $140 \mu \mathrm{M}$ insulin) and incubated at $25^{\circ} \mathrm{C}$. The reaction was followed by recording the decrease in absorbance at $340 \mathrm{~nm}$ at $30-\mathrm{s}$ intervals. As a control, the extracts were mixed with the reaction mixture containing everything except insulin and treated the same way as all other samples. From the change in absorbance of each sample was subtracted the change in absorbance of the respective control sample lacking insulin. The activity of TRX reductase (units per milligram protein) was calculated as micromoles of NADPH oxidized per minute in the extract $(1 \mathrm{mg})$ from the relation $\Delta A_{340} \times 0.12 \times 200 / 6.2$ $(25,26)$.

Transfection and chloramphenicol acetyltransferase (CAT) assay. Transient transfections of the reporter plasmid were performed by electroporation using a gene pulser (Bio-Rad Laboratories). Jurkat cells $\left(5 \times 10^{6}\right.$ cells $)$ were suspended in $300 \mu$ of culture medium (RPMI 1640 with $10 \%$ FCS) with $5 \mu \mathrm{g}$ of the reporter plasmid (phTRX-CAT), in which the hTRX promoter region ranging from -2629 to +28 was subcloned into the pCAT-Basic vector (Promega Corp., Madison, WI), and then subjected to electroporation. $24 \mathrm{~h}$ after the transfection, the cells were treated with agents (CDDP and/or BHA) for an additional $24 \mathrm{~h}$, and cell extracts were prepared by three freeze-thaw cycles in $100 \mu$ l of $0.25 \mathrm{M}$ Tris- $\mathrm{HCl}, \mathrm{pH}$ 7.8. For the measurement of CAT activity, equal amounts of total cellular protein (70 $\mu \mathrm{g}$ ), estimated by a protein assay, were incubated in the reaction mixture at $37^{\circ} \mathrm{C}$ for $2 \mathrm{~h}$, and reaction products were analyzed by TLC followed by autoradiography (29). Quantification of CAT activity (percent conversion) was performed, based on the measurement of radioactive signals using an image analyzer (Fuji Photo Film Co., Tokyo, Japan).

Flow cytometric estimation of intracellular redox state. The intracellular redox state was estimated by levels of intracellular peroxides, which were monitored by flow cytometric analysis with DCFH-DA (30). DCFH-DA is a nonpolar compound that readily diffuses into cells, where it is converted into a nonfluorescent polar derivative, 

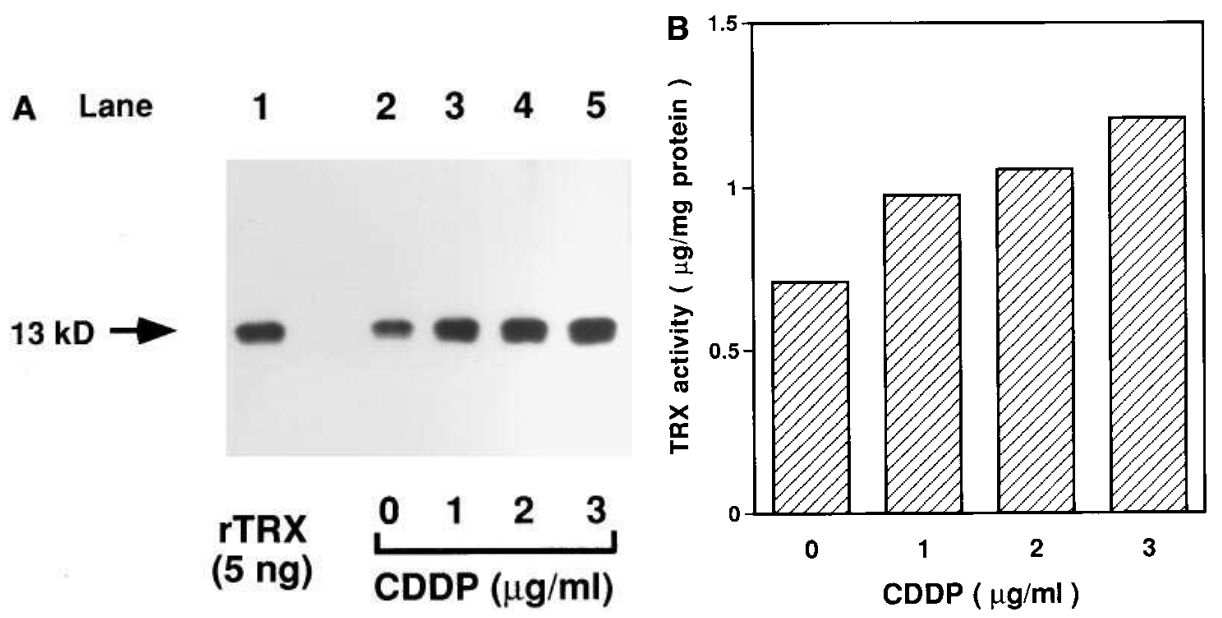

Figure 1. Effect of CDDP treatment on the expression $(A)$ and activity $(B)$ of hTRX in Jurkat cells. $(A)$ The cell lysates ( $5 \mu \mathrm{g} / \mathrm{lane})$, obtained from Jurkat cells treated with the indicated doses of CDDP for $48 \mathrm{~h}$, were electrophoresed and subjected to immunoblot analysis with anti-hTRX mAb (ADF-11 mAb). Lane 1, rTRX 5 ng (a positive control); lane 2, untreated Jurkat cells; lanes 3-5, Jurkat cells treated with $1 \mu \mathrm{g} / \mathrm{ml}$ (lane 3), $2 \mu \mathrm{g} / \mathrm{ml}$ (lane 4), or $3 \mu \mathrm{g} / \mathrm{ml}$ (lane 5) CDDP. hTRX migrates at $M_{r} 13,000$.

$(B)$ The TRX activity in the cell extracts $(40 \mu \mathrm{g})$, obtained from Jurkat cells treated with the indicated doses of CDDP for $48 \mathrm{~h}$, was determined by insulin reducing assay as described in

Methods. The values obtained from this assay were compared to the standard curve for $\mathrm{rTRX}(100-1,200 \mathrm{ng} / \mathrm{ml})$ and data were expressed as the absolute amount of TRX per milligram of total protein (micrograms per milligram protein). Results are means of duplicate determinations of a single experiment and are representative of three similar experiments.

$2^{\prime}, 7^{\prime}$-dichlorofluorescin (DCFH), by cellular esterase. DCFH is membrane impermeable and rapidly oxidizes to a highly fluorescent compound, 2', $7^{\prime}$-dichlorofluorescein (DCF), in the presence of intracellular $\mathrm{H}_{2} \mathrm{O}_{2}$ and/or other peroxides. Thus, cellular fluorescence intensity is directly proportional to levels of intracellular peroxides and can be monitored by flow cytometry. For assays, $2 \times 10^{5}$ cells were treated with agents (CDDP and/or BHA) for the indicated time, and then the culture medium was replaced with freshly prepared medium containing $5 \mu \mathrm{M}$ DCFH-DA. After $30 \mathrm{~min}$ of incubation at $37^{\circ} \mathrm{C}$, the fluorescence intensity was measured by flow cytometry (Cytoron; Ortho Diagnostic Systems K.K., Tokyo, Japan).

Establishment of hTRX-transfected clones of L929 cells. Exponentially growing L929 cells, plated at a density of $10^{5}$ cells $/ 60-\mathrm{mm}$ dish $1 \mathrm{~d}$ before transfection, were cotransfected with $20 \mu \mathrm{g}$ of the hTRX expression vector (pcDSR $\alpha \mathrm{ADF}$ ) (5) and $2 \mu \mathrm{g}$ of pSV2-neo (31) using the DEAE-dextran method (29). After $72 \mathrm{~h}, \mathrm{G} 418(200 \mu \mathrm{g} / \mathrm{ml})$ was added to the transfected cells for selection. Then, G418-resistant clones were isolated and screened for expression of hTRX protein by immunoblotting with anti-hTRX mAb (ADF-11 mAb). Another population of L929 cells was similarly transfected with the control vector $(\operatorname{pcDSR} \alpha)$ and $\mathrm{pSV} 2$-neo, and selected for G418 resistance to serve as the transfected controls.

Cytotoxicity assay. Cytotoxicity was assessed by trypan blue dye exclusion and MTT assay. For MTT assay, L929 cells $\left(5 \times 10^{3}\right.$ cells/ well), plated in a 96-well flat-bottom plate and cultured overnight, were incubated in $100 \mu \mathrm{l}$ of culture medium containing the indicated doses of agents (CDDP and/or BHA). After $20 \mathrm{~h}$ of culture at $37^{\circ} \mathrm{C}$, $10 \mu \mathrm{l}$ of MTT $(5 \mathrm{mg} / \mathrm{ml})$ was added to the wells, followed by incubation for an additional $4 \mathrm{~h}$. The resulting formazan product was solubilized in $100 \mu \mathrm{l}$ of acid-isopropanol $(0.04 \mathrm{~N} \mathrm{HCl}$ in isopropanol) and measured spectrophotometrically at $595 \mathrm{~nm}$ on an ELISA reader (microplate reader 3550; Bio-Rad Laboratories).

\section{Results}

Upregulation of $h T R X$ expression and activity in the Jurkat human $T$ cell line after exposure to $C D D P$. We first determined whether treatment with CDDP increased the expression levels of hTRX protein in the Jurkat human T cell line. As shown in Fig. $1 A$, immunoblot analysis demonstrated that the expression of hTRX protein was enhanced after exposure to CDDP $(1,2$, and $3 \mu \mathrm{g} / \mathrm{ml})$ for $48 \mathrm{~h}$. Moreover, insulin reducing assay showed that the hTRX activity was dose-dependently in- creased by treatment with 1,2 , and $3 \mu \mathrm{g} / \mathrm{ml}$ CDDP for $48 \mathrm{~h}$ in Jurkat cells (Fig. $1 \mathrm{~B}$ ). We next examined the effect of CDDP on the activity of hTRX promoter using CAT assay. Jurkat cells were transfected with phTRX-CAT, which contained the hTRX $5^{\prime}$-flanking region fused to the structural gene coding for CAT, and were treated with CDDP for $24 \mathrm{~h}$. Treatment with 1,2 , and $3 \mu \mathrm{g} / \mathrm{ml}$ CDDP resulted in a 1.6-, 2.7-, and 5.2fold increase of CAT activity, respectively (Fig. 2). These data indicated that treatment of Jurkat cells with CDDP caused transcriptional activation of the hTRX gene.

Involvement of ROI in the CDDP-induced activation of $h T R X$ gene expression. It has been suspected that increased generation of intracellular ROI is related to the biological effects of CDDP (15-19). In fact, as shown in Fig. 3, Jurkat cells treated with CDDP displayed a dose-dependent increase in the intracellular accumulation of peroxides, estimated by flow cytometric analysis with DCFH-DA. In addition, our previous

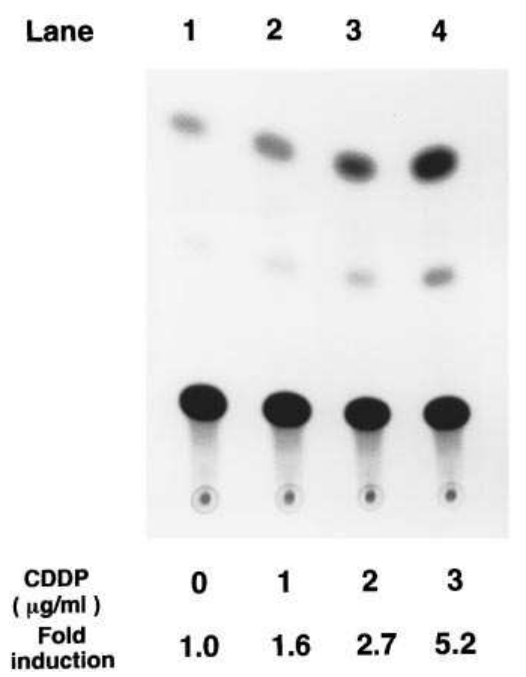

Figure 2. Effect of CDDP treatment on the activity of hTRX promoter in Jurkat cells. Jurkat cells $\left(5 \times 10^{6}\right.$ cells) were transfected with $5 \mu \mathrm{g}$ of phTRXCAT, which contained the hTRX 5'-flanking region (from -2629 to $+28)$ fused to the structural gene coding for CAT. After $24 \mathrm{~h}$ of transfection, the cells were treated with the indicated doses of CDDP for the following $24 \mathrm{~h}$. Equal amounts of the cell extracts $(70 \mu \mathrm{g})$ were used for the measurement of CAT activity. Lane 1, untreated Jurkat cells; lanes 2-4, Jurkat cells treated with $1 \mu \mathrm{g} / \mathrm{ml}$ (lane 2), $2 \mu \mathrm{g} / \mathrm{ml}$ (lane 3 ), or $3 \mu \mathrm{g} / \mathrm{ml}$ (lane 4) CDDP after transfection. 


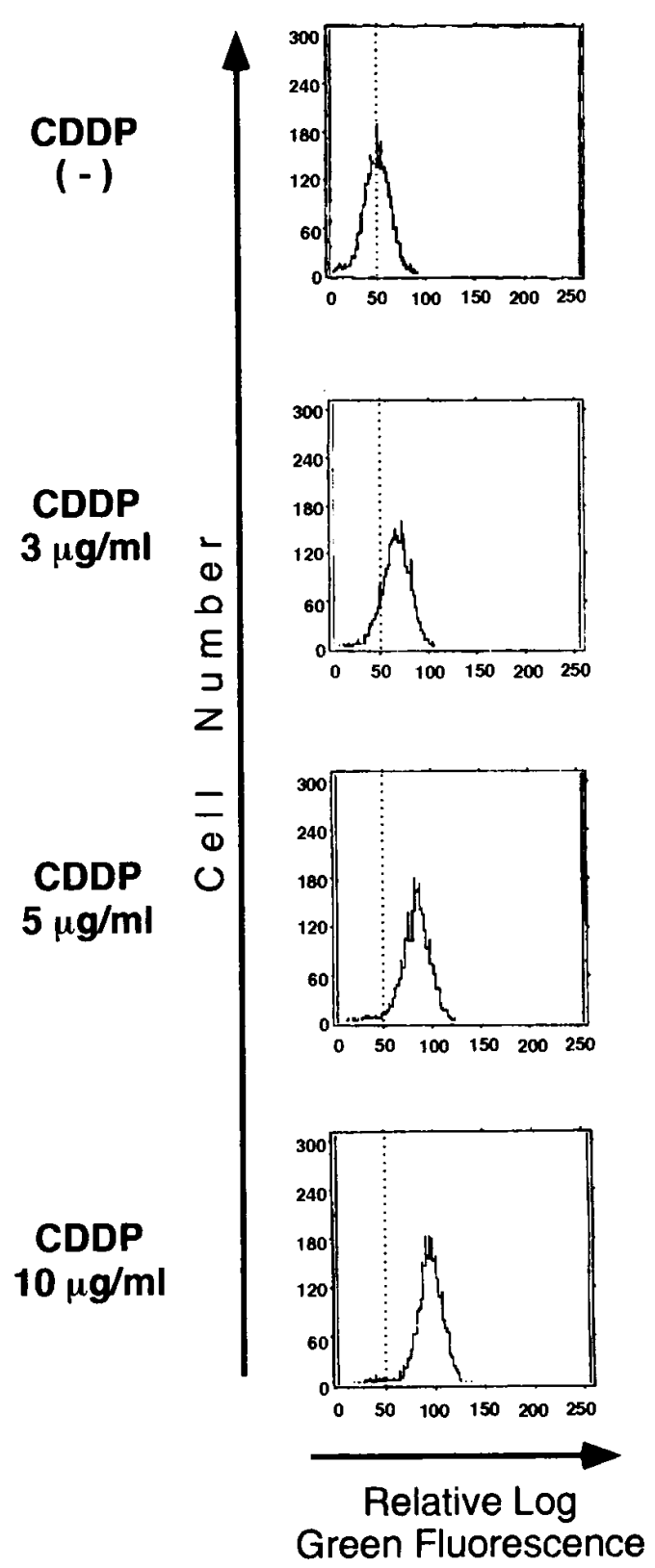

Figure 3. Effect of CDDP treatment on the fluorescence distribution of DCFH oxidation in Jurkat cells. Jurkat cells $\left(2 \times 10^{5}\right.$ cells $)$ were cultured for $6 \mathrm{~h}$ in the absence or presence of the indicated doses of $\operatorname{CDDP}(3,5$, or $10 \mu \mathrm{g} / \mathrm{ml})$, and then the culture medium was replaced with freshly prepared medium containing $5 \mu \mathrm{M}$ DCFH-DA. After 30 min of incubation at $37^{\circ} \mathrm{C}$, fluorescence intensity was measured by flow cytometry.

studies demonstrated that the expression of hTRX was induced by various oxidative stimuli, including $\mathrm{H}_{2} \mathrm{O}_{2}$, x-ray, and ultraviolet exposure $(5,11,12)$. Therefore, to determine whether ROI are involved in the CDDP-induced overexpression of hTRX, we examined the effect of an antioxidant, BHA, on the CDDP-induced transactivation of hTRX promoter. BHA is a phenolic, lipid-soluble, chain-breaking antioxidant, and has been shown to inhibit an intracellular signaling pathway regulated by ROI, such as nuclear factor-кB activation $(32,33)$. As shown in Fig. 4, CAT assay with the hTRX promoter-reporter gene construct (phTRX-CAT) demonstrated that the CDDP-

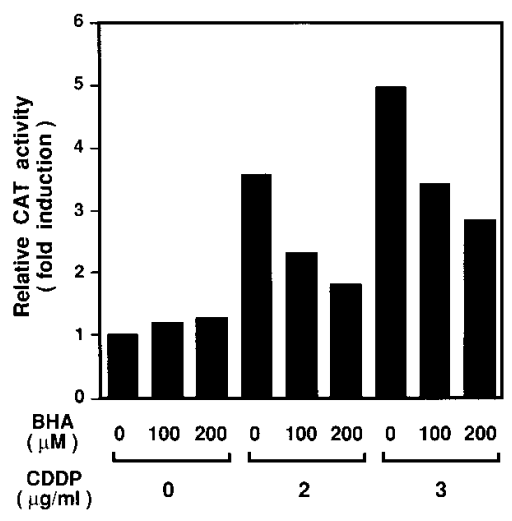

Figure 4. Effect of BHA on the CDDPinduced transactivation of hTRX promoter in Jurkat cells. Jurkat cells $\left(5 \times 10^{6}\right.$ cells $)$ were transfected with $5 \mu \mathrm{g}$ of phTRX-CAT. After $24 \mathrm{~h}$ of transfection, the cells were cultured for the following $24 \mathrm{~h}$ with no drug, BHA alone (100 $\mu \mathrm{M}$ or $200 \mu \mathrm{M})$, or CDDP $(2 \mu \mathrm{g} / \mathrm{ml}$ or $3 \mu \mathrm{g} /$ $\mathrm{ml}$ ) in the absence or presence of BHA (100

$\mu \mathrm{M}$ or $200 \mu \mathrm{M})$. Equal amounts of the cell extracts $(70 \mu \mathrm{g})$ were used for the measurement of CAT activity. Each bar represents the relative CAT activity (fold induction) in comparison with the untreated cells. This experiment was performed three times with similar results.

induced transactivation of hTRX promoter was dose-dependently inhibited in the presence of BHA $(100 \mu \mathrm{M}$ or $200 \mu \mathrm{M})$ in Jurkat cells. As expected, incubation of Jurkat cells with BHA decreased the intracellular accumulation of peroxides after treatment with CDDP (data not shown). These results indicated that the CDDP-induced activation of hTRX gene expression might be dependent on the increased generation of intracellular ROI.

Establishment of $h T R X$-overexpressing derivatives of the L929 murine fibrosarcoma cell line. To evaluate the biological significance of the hTRX induction by CDDP, we determined whether overexpression of hTRX affected the cellular sensitivity to CDDP. We established hTRX-overexpressing derivatives of the L929 murine fibrosarcoma cell line by stable transfection with the hTRX cDNA. The hTRX expression vector ( $p c D S R \alpha A D F)$ was introduced into L929 cells with the selectable pSV2-neo plasmid, and two clones with resistance to G418 $(200 \mu \mathrm{g} / \mathrm{ml})$ were selected. As a control, L929 cells transfected with the control vector $(\operatorname{pcDSR} \alpha)$ and $\mathrm{pSV} 2$-neo were similarly selected for G418 resistance, and two clones were isolated. As shown in Fig. 5, the hTRX-transfected clones, TRX-8 and TRX-14, demonstrated a readily detectable expression of hTRX protein by immunoblot analysis with anti-hTRX mAb, whereas the parental L929 and control transfected cells, Neo-1 and Neo-5, did not. To evaluate the function of overexpressed hTRX protein, the TRX activity in the parental and transfected clones was analyzed by insulin reducing assay. The control transfected cells, Neo-1 and Neo-5, and the parental L929 cells displayed almost the same levels of TRX activity, which might reflect the activity of endogenous mouse TRX. In contrast, the hTRX-transfected cell lines TRX-8 and TRX-14 showed a 1.8- and 2.9-fold increase in TRX activity over the parental L929 cells, respectively. However, the parental and transfected L929 cells displayed no significant differences in the TRX reductase activity (Table I).

Effect of the overexpression of $h T R X$ on CDDP-induced cytotoxicity. The parental and transfected L929 cells were examined by viable cell counts using trypan blue exclusion and MTT assay for sensitivity to cytotoxicity induced by continuous exposure ( $24 \mathrm{~h})$ to CDDP. As shown in Fig. 6, the hTRX- 


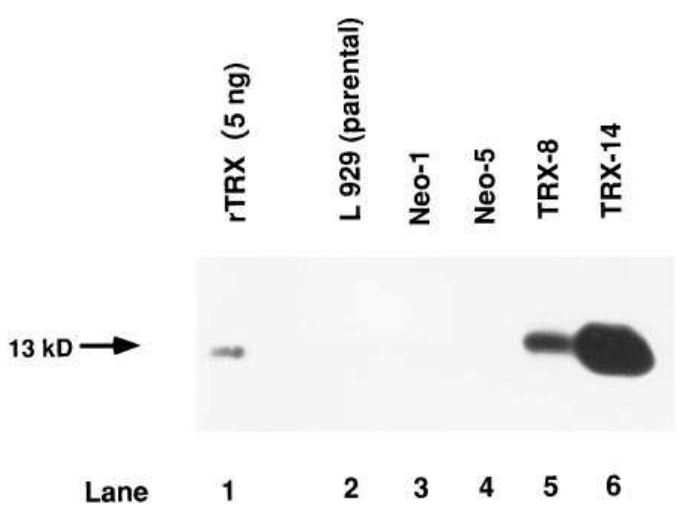

Figure 5. Expression of hTRX protein in the parental and transfected L929 cells. Cell lysates were prepared from the parental and transfected L929 cells. Equal amounts of the cell lysates (10 $\mu \mathrm{g} / \mathrm{lane})$ were electrophoresed and subjected to immunoblot analysis with antihTRX mAb (ADF-11 mAb). Lane 1, rTRX 5 ng (a positive control); lane 2, parental L929 cells; lane 3, Neo-1 (control transfected cells); lane 4, Neo-5 (control transfected cells); lane 5, TRX-8 (hTRX-transfected cells); lane 6, TRX-14 (hTRX-transfected cells). hTRX migrates at $\mathrm{M}_{\mathrm{r}} 13,000$.

transfected cells, TRX-8 and TRX-14, were more resistant to CDDP-induced cytotoxicity, compared to the parental L929 and control transfected cells, Neo-1 and Neo-5. Because hTRX has been shown to play a protective role against various oxidative stresses $(10,11)$ by functioning as a redox buffer, we estimated the intracellular redox state after CDDP treatment in the hTRX-transfected and control cells. As shown in Fig. 7, flow cytometric analysis with DCFH-DA demonstrated that exposure to CDDP caused a significant increase in the intracellular accumulation of peroxides in the parental L929 and control transfected cells, but not in the hTRX-transfected cells. Furthermore, we found that the CDDP-induced cytotoxicity decreased dose-dependently in the presence of an antioxidant, BHA, in the parental L929 cells (Fig. 8). This preventive effect of BHA on CDDP-induced cytotoxicity was also observed in another cell line, Jurkat, and was accompanied by a decreased accumulation of intracellular peroxides after CDDP treatment (data not shown). These results indicated that CDDP-induced cytotoxicity might be due, at least in part, to an increased generation of ROI and that hTRX might confer cellular resistance to CDDP by scavenging intracellular toxic oxidants generated by this agent.

\section{Discussion}

CDDP remains one of the most effective chemotherapeutic agents for cancer therapy. However, its potential is limited by the presence of intrinsic or acquired resistance to this agent. Thus, it has been of particular importance to clarify the precise mechanisms by which resistance to CDDP arises and to develop efficient therapeutic strategies to overcome the resistance to CDDP treatment. Although the mechanisms resulting in cellular resistance to CDDP have been explained by several different factors, including reduced membrane permeability, enhanced drug detoxification, and increased efficiency of DNA repair processes $(13,14)$, they remain complex and as yet are not fully understood. In the present study, we have demonstrated that CDDP increases the expression of hTRX at
Table I. The TRX and TRX Reductase Activity in the Parental and Transfected L929 Cells

\begin{tabular}{lcc}
\hline & TRX activity & $\begin{array}{c}\text { TRX reductase } \\
\text { activity }\end{array}$ \\
\hline Parental L929 & 2.16 & U/mg protein \\
Neo-1 & 2.08 & 0.0209 \\
Neo-5 & 2.07 & 0.0221 \\
TRX-8 & 3.85 & 0.0205 \\
TRX-14 & 6.34 & 0.0212 \\
& & 0.0220
\end{tabular}

The activity of TRX and TRX reductase in the parental and transfected L929 cells was determined by insulin reducing assay. For determination of the TRX activity, after preincubation with the DTT activation buffer, equal amounts of cell extracts $(20 \mu \mathrm{g})$ were mixed with the reaction mixture (0.1 M Tris-Cl (pH 7.5), 2 mM EDTA, $0.2 \mathrm{mM} \mathrm{NADPH,} 0.4 \mathrm{U} / \mathrm{ml}$ human TRX reductase, $140 \mu \mathrm{M}$ insulin) and incubated at $25^{\circ} \mathrm{C}$, followed by recording the decrease in absorbance at $340 \mathrm{~nm}$. As a control, the preincubated extracts were mixed with the reaction mixture containing everything except insulin. The obtained values were compared to the standard curve for rTRX (100-1,200 ng/ml). Data (micrograms per milligram protein) were expressed as the absolute amount of TRX per milligram of total protein. For determination of the TRX reductase activity, equal amounts of cell extracts $(5 \mu \mathrm{g})$ were mixed with the reaction mixture (0.1 M Tris- $\mathrm{Cl}$ (pH 7.5), $2 \mathrm{mM}$ EDTA, $0.2 \mathrm{mM}$ NADPH, $10 \mu \mathrm{M}$ rTRX, $140 \mu \mathrm{M}$ insulin) and incubated at $25^{\circ} \mathrm{C}$, followed by recording the decrease in absorbance at $340 \mathrm{~nm}$. As a control, the extracts were mixed with the reaction mixture containing everything except insulin. Data (units per milligram protein) were calculated as micromoles of NADPH oxidized per min per milligram of total protein from the relation $\Delta A_{340} \times$ $0.12 \times 200 / 6.2$. Results are means of duplicate determinations of a single experiment and are representative of two similar experiments.

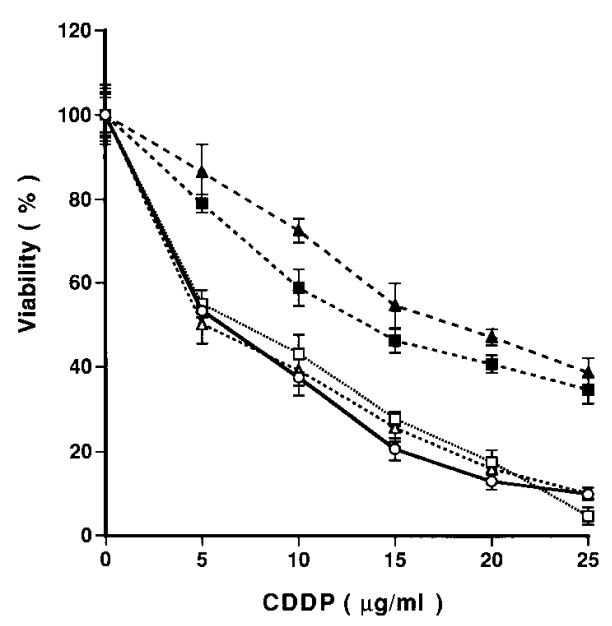

Figure 6. Effect of continuous exposure to CDDP on the cell viability of parental and transfected L929 cells. Cells $\left(5 \times 10^{4} /\right.$ well $)$ from each

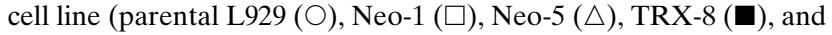
TRX-14 ( $\mathbf{\Delta})$ were plated in a 24-well flat-bottom plate, cultured overnight, and then exposed to the indicated doses of CDDP for $24 \mathrm{~h}$. Cell viability (percent viability) was determined by viable cell counts using trypan blue exclusion. Data were expressed as the percentage of the viable cell number without CDDP treatment. The means and SDs of triplicate cultures are shown. Cell viability assessed by MTT assay yielded similar results. 


\section{parental}

L929

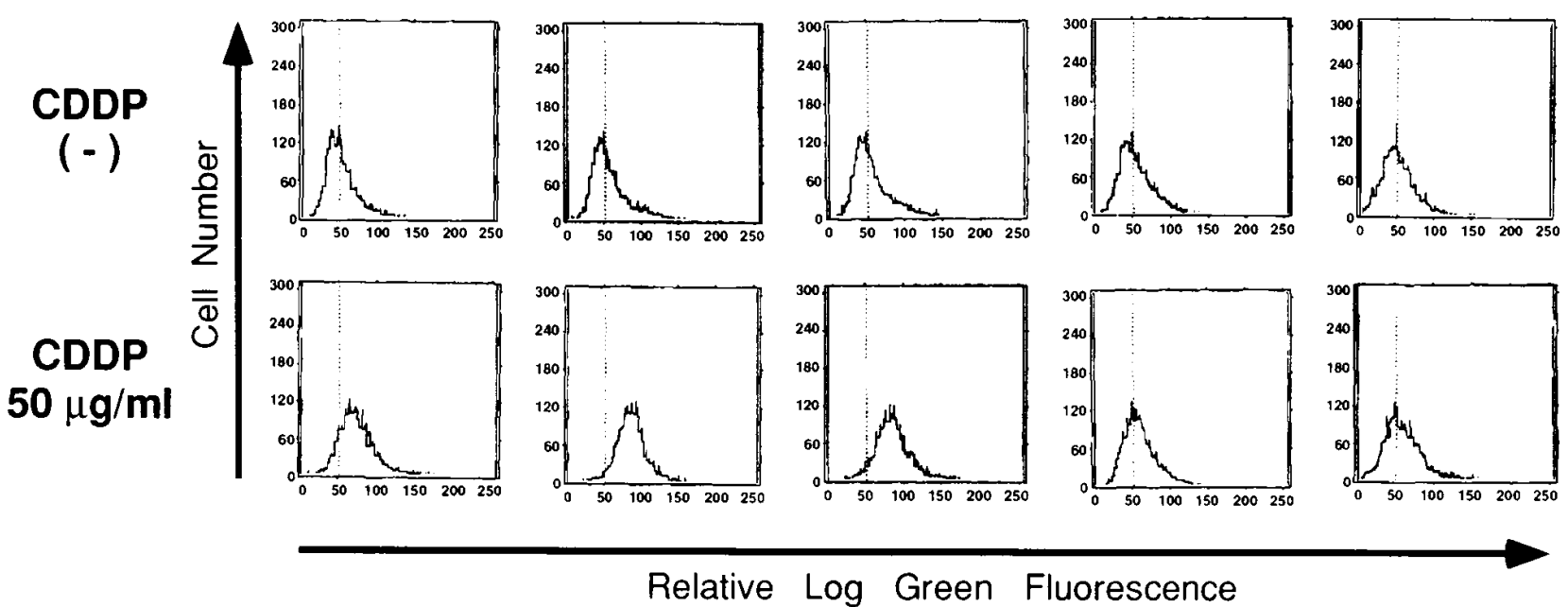

Figure 7. Effect of CDDP treatment on the fluorescence distribution of DCFH oxidation in the parental and transfected L929 cells. Cells $(2 \times$ $10^{5}$ cells) from each cell line (parental L929, Neo-1, Neo-5, TRX-8, and TRX-14) were cultured for $6 \mathrm{~h}$ in the absence or presence of CDDP (50 $\mu \mathrm{g} / \mathrm{ml}$ ), and then the culture medium was replaced with freshly prepared medium containing $5 \mu \mathrm{M}$ DCFH-DA. After 30 min of incubation at $37^{\circ} \mathrm{C}$, fluorescence intensity was measured by flow cytometry.

the transcriptional level, and that overexpression of hTRX confers cellular resistance to CDDP-induced cytotoxicity. These observations indicate that hTRX may play an important role in the acquisition of CDDP resistance.

hTRX has been reported to be a stress-inducible protein, whose expression is enhanced by various oxidative stimuli. Previous studies have shown that the expression of hTRX is upregulated after exposure to $\mathrm{H}_{2} \mathrm{O}_{2}$, x-ray, or ultraviolet irradiation $(5,11,12)$. Moreover, according to our recent observations, the hTRX promoter has a novel cis-acting regulatory element responsive for a variety of oxidative stimuli, such as $\mathrm{H}_{2} \mathrm{O}_{2}$, sulfhydryl-oxidizing agents, and ultraviolet irradiation (Taniguchi, Y., and J. Yodoi, manuscript in preparation). In the present study, we demonstrated that treatment with CDDP caused transcriptional activation of the hTRX gene in the Jurkat human $\mathrm{T}$ cell line. Furthermore, this activation was shown to be inhibited by an antioxidant, BHA, suggesting that CDDP enhanced the expression of hTRX through increased generation of ROI. In addition, CDDP has been reported to induce enhanced expression of several other genes, such as c-jun, c-fos, and HIV (34-36). Because these genes are also known to be transactivated by oxidative stress $(37,38)$, it is likely that ROI may function as a common signaling mediator in the modulation of gene expression after CDDP treatment.

There is growing evidence that the cytotoxic activity of CDDP is closely associated with increased generation of ROI. It has been reported that generation of ROI and subsequent peroxidation of membrane lipids are involved in CDDPinduced nephrotoxicity and that administration of free radical scavengers or antioxidants, such as SOD and $\alpha$-tocopherol, protects the kidney from CDDP-induced toxicity in in vivo animal models (15-17). In addition, Sodhi and Gupta (18) have reported that murine macrophages treated with CDDP show increased production and release of $\mathrm{H}_{2} \mathrm{O}_{2}$ and superoxide anion in vitro. Masuda et al. (19) have demonstrated that the direct interaction of CDDP and DNA generates superoxide an- ion and hydroxyl radical in a cell-free system. In the present study, we found that exposure to CDDP caused a dose-dependent increase in the intracellular accumulation of peroxides in murine L929 and human Jurkat T cells. Furthermore, we demonstrated that an antioxidant, BHA, inhibited the cytotoxic effect of CDDP in these cell lines, possibly by scavenging intracellular toxic oxidants. These observations indicate that increased production of intracellular ROI may, at least in part,

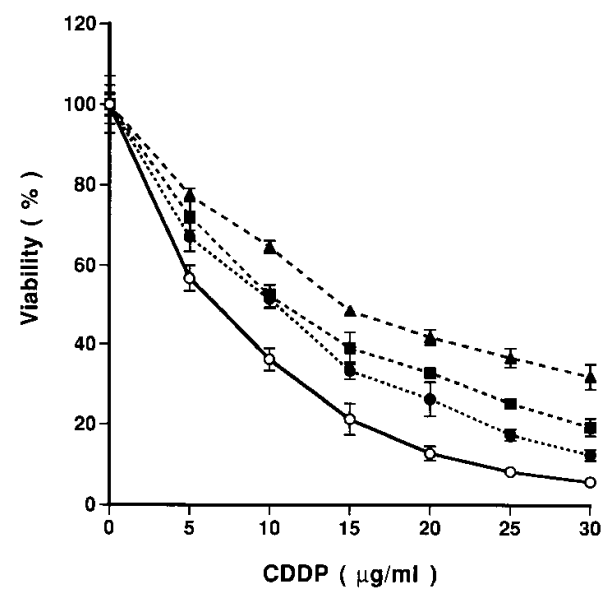

Figure 8. Effect of BHA on the cell viability of L929 cells after exposure to CDDP. L929 cells $\left(5 \times 10^{3} /\right.$ well $)$ were plated in a 96 -well flatbottom plate, cultured overnight, and then exposed to CDDP in the absence $(\bigcirc)$ or presence of BHA $(50 \mu \mathrm{M}[\mathbf{\bullet}], 100 \mu \mathrm{M}[\mathbf{\square}], 150$ $\mu \mathrm{M}[\mathbf{\Delta}])$. After $20 \mathrm{~h}$ of culture at $37^{\circ} \mathrm{C}$, MTT was added to the wells, followed by incubation for an additional $4 \mathrm{~h}$. The resulting formazan product was measured spectrophotometrically at $595 \mathrm{~nm}$ on an ELISA reader. Cell viability (percent viability) was expressed as the percentage of the OD value obtained from the cells without CDDP treatment. The means and SDs of triplicate cultures are shown. 
be responsible for CDDP-induced cytotoxicity. Recently, attention has been directed to oxidative damage as a common mediator in chemotherapeutic drug-induced cell death, particularly as a signal in apoptotic cell death (39). For example, $b c l-2$ gene product, which is known to prevent apoptosis by functioning as an antioxidant $(40,41)$, was reported to confer cellular resistance to CDDP $(42,43)$. This finding provides further support for the critical role of oxidative stress in CDDPinduced cytotoxicity.

hTRX can function not only as a hydrogen donor for various proteins, but also as a scavenger of ROI. rTRX has been shown to reduce ROI, such as $\mathrm{H}_{2} \mathrm{O}_{2}$ and hydroxyl radical, efficiently in vitro (9). Moreover, a family of TRX-dependent peroxide reductase has been recently identified from yeast and mammalian cells, which directly reduces $\mathrm{H}_{2} \mathrm{O}_{2}$ and various alkyl hydroperoxides with the use of hydrogens provided by the TRX system (44). These studies indicate that hTRX may play an important role in the cellular defense mechanisms against oxidative stress. In fact, rTRX has a protective activity against $\mathrm{H}_{2} \mathrm{O}_{2}$-induced cytotoxicity in murine endothelial cells (11). In addition, in a human histiocytic lymphoma cell line, pretreatment with $\mathrm{rTRX}$ can inhibit TNF $\alpha$-induced cytotoxicity, in which the generation of ROI seems to be involved (10). In the present study, we demonstrated that the hTRX-transfected L929 cells showed reduced sensitivity to CDDP, and that they did not display a significant increase in the intracellular accumulation of peroxides after exposure to CDDP. Similar results were observed in the parental L929 cells treated with an antioxidant, BHA, suggesting that hTRX and BHA had a protective activity against CDDP-induced cytotoxicity through a common mechanism. Therefore, it is quite conceivable that endogenous hTRX has a protective role against CDDP-induced cytotoxicity, by scavenging toxic ROI generated by CDDP.

Besides the scavenging activity of intracellular ROI, however, other mechanisms may also contribute to the protective effect of hTRX against CDDP. CDDP is a potent electrophile that reacts with any nucleophiles, including the sulfhydryl groups (on proteins) and nucleophilic groups (on nucleic acids) $(13,45)$. Several studies have suggested that intracellular thiols, such as glutathione or metallothioneins, affect cellular sensitivity to CDDP, by covalently binding to CDDP and detoxifying it in the cytosol $(13,45-50)$. Similarly, it is likely that hTRX, a potent nucleophile with active sulfhydryl groups $(1,2)$, protects cells by directly intercepting reactive platinum complexes in the cytosol before they can react with other proteins or nucleic acids. Recently, we have reported that hTRX plays a critical role in the regulation of intracellular thiols, especially glutathione $(51,52)$. However, in the present study, the hTRX-mediated regulation of the glutathione system may not be attributed to cellular resistance to CDDP, because overexpression of hTRX did not result in a significant change of intracellular glutathione levels in L929 cells (data not shown). Alternatively, inactivation of hTRX by direct binding to CDDP may be one of the key processes in the induction of CDDP-mediated apoptotic cell death. hTRX seems to have crucial roles in the regulation of apoptosis, because it controls various cellular functions, including the redox regulation of several enzymes and transcription factors $(1,2,5,7,8)$. In fact, we have demonstrated that oxidation and inactivation of intracellular protein thiols other than glutathione, such as hTRX, may be one of the critical processes in the induction of apop- tosis in human lymphocytes treated with a sulfhydryl-specific oxidant, diamide (53).

Additionally, hTRX may be involved in the DNA replication or repair processes after CDDP exposure, because TRX is a hydrogen donor for ribonucleotide reductase, the essential enzyme for the biosynthesis of deoxyribonucleotides and DNA $(1,2)$. It was reported that ribonucleotide reductase from E. coli and mammalian cells was inhibited by CDDP in vitro $(54,55)$, and that inactivation of this enzyme had significant effects on the DNA repair processes after treatment with DNA-damaging chemotherapeutic agents $(56,57)$. Moreover, mammalian glutaredoxin, another hydrogen donor for ribonucleotide reductase $(1,2)$, was also shown to be inactivated by CDDP in vitro (58). Because the activity of ribonucleotide reductase depends on the generation of its active-site dithiol mediated by the TRX or glutaredoxin system $(1,2)$, overexpression of hTRX may enhance the efficiency of DNA replication or repair after CDDP treatment by providing required deoxyribonucleotides through regulation of the activity of this enzyme.

Although we could not find any significant differences in the TRX reductase activity between the control and hTRXoverexpressing L929 cells in the present study, the TRX reductase activity may also affect cellular sensitivity to CDDP. According to our preliminary observation, the enzyme activity of TRX reductase decreases after treatment with CDDP in cultured cells. Recent studies have shown that TRX reductase not only catalyzes the reduction of oxidized TRX by NADPH, but also reduces hydroperoxides directly or via activation of a selenium-dependent peroxidase in a cell-free system $(59,60)$. Moreover, inactivation of the disulfide reducing activity of TRX reductase, induced by an alkylating agent, has been reported to be accompanied by a large increase in NADPH oxidase activity, which will produce ROI and cause oxidative stress (61). Therefore, it may be possible that increased generation of intracellular ROI by CDDP exposure is attributed to impairment of the TRX system, especially caused by the inactivation of TRX reductase, and that overexpressed hTRX compensates for the decreased enzyme activity of TRX reductase to prevent alterations of the intracellular redox state. Further investigation is needed to clarify the role of TRX reductase in CDDP-induced cytotoxicity.

Recently, several investigators have found that some CDDP-resistant cell lines have higher levels of hTRX expression $(23,24)$. Moreover, it has been shown that hTRX-antisense transfectants of a human bladder cancer cell line display enhanced sensitivity against CDDP and other ROI-generating chemotherapeutic agents, such as doxorubicin, mitomycin $\mathrm{C}$, and etoposide (24). Taken together with our results in this paper, these observations indicate the critical role of hTRX in the acquisition of CDDP resistance, although further studies are needed to elucidate the precise mechanism by which hTRX provides cellular resistance to CDDP. To validate our results, however, it remains to be determined whether the results obtained from these in vitro studies are also observed in in vivo animal models or clinical situations. Studies in animal models are now under way to clarify the critical role of hTRX in CDDP resistance in vivo. A variety of human cancer cells have been reported to show enhanced expression of hTRX, which may be induced by persistent exposure to various oxidative stresses (62). Therefore, the development of pharmacological or genetical methods to modulate the expression and/or 
activity of hTRX may be a rational therapeutic strategy to overcome CDDP resistance in human cancer cells.

\section{Acknowledgments}

We thank Dr. T. Tsuruo (University of Tokyo, Tokyo, Japan), Dr. M. Kuwano (University of Kyushu, Fukuoka, Japan), and Dr. H. Nakamura (Kyoto University, Kyoto, Japan) for their stimulating discussions, Dr. T. Maruyama for his excellent technical assistance, and Ms. Y. Kanekiyo and Ms. C. Ogawa for their secretarial help.

This work was supported by a grant-in-aid for Scientific Research on Priority Areas from the Ministry of Education, Science and Culture of Japan.

\section{References}

1. Holmgren, A. 1985. Thioredoxin. Annu. Rev. Biochem. 54:237-271.

2. Holmgren, A. 1989. Thioredoxin and glutaredoxin systems. J. Biol. Chem. 264:13963-13966.

3. Tagaya, Y., M. Okada, K. Sugie, T. Kasahara, N. Kondo, J. Hamuro, K. Matsushima, C.A. Dinarello, and J. Yodoi. 1988. IL-2 receptor (p55)/Tac inducing factor: purification and characterization of ATL-derived factor (ADF). $J$. Immunol. 140:2613-2620.

4. Tagaya, Y., Y. Maeda, A. Mitsui, N. Kondo, H. Matsui, J. Hamuro, N. Brown, K.-i. Arai, T. Yokota, H. Wakasugi, et al. 1989. ATL-derived factor (ADF), an IL-2 receptor/Tac inducer homologous to thioredoxin: possible involvement of dithiol-reduction in the IL-2 receptor induction. EMBO (Eur. Mol. Biol. Organ.) J. 8:757-764.

5. Yodoi, J., and T. Uchiyama. 1992. Diseases associated with HTLV-I: virus, IL-2 receptor dysregulation and redox regulation. Immunol. Today. 13: $405-411$.

6. Gasdaska, P.Y., J.E. Oblong, I.A. Cotgreave, and G. Powis. 1994. The predicted amino acid sequence of human thioredoxin is identical to that of the autocrine growth factor human adult T-cell leukemia derived factor (ADF): thioredoxin mRNA is elevated in some human tumors. Biochim. Biophys. Acta. 1218:292-296.

7. Okamoto, T., H. Ogiwara, T. Hayashi, A. Mitsui, T. Kawabe, and J. Yodoi. 1992. Human thioredoxin/adult T cell leukemia-derived factor activates the enhancer binding protein of human immunodeficiency virus type 1 by thiol redox control mechanism. Int. Immunol. 4:811-819.

8. Abate, C., L. Patel, F.J. Rauscher III, and T. Curran. 1990. Redox regulation of Fos and Jun DNA-binding activity in vitro. Science (Wash. DC). 249: 1157-1161.

9. Mitsui, A., T. Hirakawa, and J. Yodoi. 1992. Reactive oxygen-reducing and protein-refolding activities of adult $\mathrm{T}$ cell leukemia-derived factor/human thioredoxin. Biochem. Biophys. Res. Commun. 186:1220-1226.

10. Matsuda, M., H. Masutani, H. Nakamura, S. Miyajima, A. Yamauchi, S. Yonehara, A. Uchida, K. Irimajiri, A. Horiuchi, and J. Yodoi. 1992. Protective activity of ATL-derived factor (ADF) against tumor necrosis factor-dependent cytotoxicity on U937 cells. J. Immunol. 147:3837-3841.

11. Nakamura, H., M. Matsuda, K. Furuke, Y. Kitaoka, S. Iwata, K. Toda, T. Inamoto, Y. Yamaoka, K. Ozawa, and J. Yodoi. 1994. Adult T cell leukemiaderived factor/human thioredoxin protects endothelial F-2 cell injury caused by activated neutrophils or hydrogen peroxide. Immunol. Lett. 42:75-80.

12. Sachi, Y., K. Hirota, H. Masutani, K. Toda, T. Okamoto, M. Takigawa, and J. Yodoi. 1995. Induction of ADF/TRX by oxidative stress in keratinocytes and lymphoid cells. Immunol. Lett. 44:189-193.

13. Chu, G. 1994. Cellular response to cisplatin. J. Biol. Chem. 269:787-790.

14. Timmer-Bosscha, H., N.H. Mulder, and E.G.E. de Vries. 1992. Modulation of cis-diamminedichloroplatinum (II) resistance: a review. Br. J. Cancer. 66:227-238.

15. McGinness, J.E., P.H. Proctor, H.B. Demopoulos, J.A. Hokanson, and D.S. Kirkpatrick. 1978. Amelioration of cis-platinum nephrotoxicity by Orgotein (superoxide dismutase). Physiol. Chem. Phys. 10:267-277.

16. Sugihara, K., and M. Gemba. 1986. Modification of cisplatin toxicity by antioxidants. Jpn. J. Pharmacol. 40:353-355.

17. Hannemann, J., and K. Baumann. 1988. Cisplatin-induced lipid peroxidation and decrease of gluconeogenesis in rat kidney cortex: different effects of antioxidants and radical scavengers. Toxicology. 51:119-132.

18. Sodhi, A., and P. Gupta. 1986. Increased release of hydrogen peroxide $\left(\mathrm{H}_{2} \mathrm{O}_{2}\right)$ and superoxide anion $\left(\mathrm{O}_{2}^{-}\right)$by murine macrophages in vitro after cisplatin treatment. Int. J. Immunopharmacol. 8:709-714.

19. Masuda, H., T. Tanaka, and U. Takahama. 1994. Cisplatin generates superoxide anion by interaction with DNA in a cell-free system. Biochem. Biophys. Res. Commun. 203:1175-1180.

20. Makino, S., H. Masutani, N. Maekawa, I. Konishi, S. Fujii, R. Yamamoto, and J. Yodoi. 1992. Adult T-cell leukemia-derived factor/thioredoxin expression on the HTLV-I transformed T-cell lines: heterogeneous expression in
ATL-2 cells. Immunology. 76:578-583.

21. Fujii, S., Y. Nanbu, H. Nonogaki, I. Konishi, T. Mori, H. Masutani, and J. Yodoi. 1991. Coexpression of adult T-cell leukemia-derived factor, a human thioredoxin homologue, and human papilloma virus DNA in neoplastic cervical squamous epithelium. Cancer (Phila.). 68:1583-1591.

22. Nakamura, H., H. Masutani, Y. Tagaya, A. Yamauchi, T. Inamoto, Y. Nanbu, S. Fujii, K. Ozawa, and J. Yodoi. 1992. Expression and growth-promoting effect of adult T-cell Leukemia-derived factor: a human thioredoxin homologue in hepatocellular carcinoma. Cancer (Phila.). 69:2091-2097.

23. Huston, K., D. Silberstein, and D.R. Spriggs. 1994. Eosinophil cytotoxicity enhancing factor (ECEF) overexpression in human cancer cells with acquired cisplatin resistance. Proc. Am. Assoc. Cancer Res. Annual Meeting. 35: 2611. (Abstr.)

24. Yokomizo, A., M. Ono, H. Nanri, Y. Makino, T. Ohga, M. Wada, T. Okamoto, J. Yodoi, M. Kuwano, and K. Kohno. 1995. Cellular levels of thioredoxin associated with drug sensitivity to cisplatin, mitomycin $\mathrm{C}$, doxorubicin, and etoposide. Cancer Res. 55:4293-4296.

25. Kitaoka, Y., K. Sorachi, H. Nakamura, H. Masutani, A. Mitsui, F. Kobayashi, T. Mori, and J. Yodoi. 1995. Detection of adult T-cell leukemia-derived factor/human thioredoxin in human serum. Immunol. Lett. 41:155-161.

26. Luthman, M., and A. Holmgren. 1982. Rat liver thioredoxin and thioredoxin reductase: purification and characterization. Biochemistry. 21:6628-6633.

27. Holmgren, A., and M. Björnstedt. 1995. Thioredoxin and thioredoxin reductase. Methods Enzymol. 252:199-208.

28. Oblong, J.E., P.Y. Gasdaska, K. Sherrill, and G. Powis. 1993. Purification of human thioredoxin reductase: properties and characterization by absorption and circular dichroism spectroscopy. Biochemistry. 32:7271-7277.

29. Sambrook, J., E.F. Fritsch, and T. Maniatis. 1989. Molecular Cloning: A Laboratory Manual. 2nd ed. Cold Spring Harbor Laboratory Press, Cold Spring Harbor, NY. 16.30-16.65.

30. Bass, D.A., J.W. Parce, L.R. Dechatelet, P. Szejda, M.C. Seeds, and M. Thomas. 1983. Flow cytometric studies of oxidative product formation by neutrophils: a graded response to membrane stimulation. J. Immunol. 130:19101917.

31. Southern, P.J., and P. Berg. 1982. Transformation of mammalian cells to antibiotic resistance with a bacterial gene under control of the SV40 early region promoter. J. Mol. Appl. Genet. 1:327-341.

32. Israel, N., M.-A. Gougerot-Pocidalo, F. Aillet, and J.-L. Virelizier. 1992. Redox status of cells influences constitutive or induced NF-kB translocation and HIV long terminal repeat activity in human $\mathrm{T}$ and monocytic cell lines. $J$. Immunol. 149:3386-3393.

33. Schulze-Osthoff, K., R. Beyaert, V. Vandevoorde, G. Haegeman, and W. Fiers. 1993. Depletion of the mitochondrial electron transport abrogates the cytotoxic and gene-inductive effects of TNF. EMBO (Eur. Mol. Biol. Organ.) J. 12:3095-3104.

34. Hollander, M.C., and A.J. Fornance, Jr. 1989. Induction of fos RNA by DNA-damaging agents. Cancer Res. 49:1687-1692.

35. Rubin, E., S. Kharbanda, H. Gunji, R. Weichselbaum, and D. Kufe. 1992. cis-diamminedichloroplatinum (II) induces c-jun expression in human myeloid leukemia cells: potential involvement of a protein kinase C-dependent signaling pathway. Cancer Res. 52:878-882.

36. Zoumpourlis, V., D.J. Kerr, and D.A. Spandidos. 1992. Carboplatin as opposed to cisplatin does not stimulate the expression of the human immunodeficiency virus long terminal repeat sequences. Biochem. Pharmacol. 43:650 654.

37. Devary, Y., R.A. Gottlieb, L.F. Lau, and M. Karin. 1991. Rapid and preferential activation of the c-jun gene during the mammalian UV response. Mol. Cell. Biol. 11:2804-2811.

38. Schreck, R., P. Rieber, and P.A. Baeuerle. 1991. Reactive oxygen intermediates as apparently widely used messengers in the activation of the NF- $\mathrm{kB}$ transcription factor and HIV-1. EMBO (Eur. Mol. Biol. Organ.) J. 10:22472258

39. Buttke, T.M., and P.A. Sandstrom. 1994. Oxidative stress as a mediator of apoptosis. Immunol. Today. 15:7-10.

40. Hockenbery, D.M., Z.N. Oltvai, X.-M. Yin, C.L. Milliman, and S.J. Korsmeyer. 1993. Bcl-2 functions in an antioxidant pathway to prevent apoptosis. Cell. 75:241-251.

41. Kane, D.J., T.A. Sarafian, R. Anton, H. Hahn, E.B. Gralla, J.S. Valentine, T. Örd, and D.E. Bredesen. 1993. Bcl-2 inhibition of neuronal death: decreased generation of reactive oxygen species. Science (Wash. DC). 262:12741277.

42. Miyashita, T., and J.C. Reed. 1993. Bcl-2 oncoprotein blocks chemotherapy-induced apoptosis in a human leukemia cell line. Blood. 81:151-157.

43. Dole, M., G. Nunez, A.K. Merchant, J. Maybaun, C.K. Rode, C.A Bloch, and V.P. Castle. 1994. Bcl-2 inhibits chemotherapy-induced apoptosis in neuroblastoma. Cancer Res. 54:3253-3259.

44. Chae, H.Z., S.J. Chung, and S.G. Rhee. 1994. Thioredoxin-dependent peroxide reductase from yeast. J. Biol. Chem. 269:27670-27678.

45. Dedon, P.C., and R.F. Borch. 1987. Characterization of the reactions of platinum antitumor agents with biologic and nonbiologic sulfur-containing nucleophiles. Biochem. Pharmacol. 36:1955-1964.

46. Zelazowski, A.J., J.S. Garvey, and J.D. Hoeschele. 1984. In vivo and in vitro binding of platinum to metallothionein. Arch. Biochem. Biophys. 229:246-252. 
47. Meijer, C., N.H. Mulder, G.A.P. Hospers, D.R.A. Uges, and E.G.E. de Varies. 1990. The role of glutathione in resistance to cisplatin in a human small cell lung cancer cell line. Br. J. Cancer. 62:72-77.

48. Godwin, A.K., A. Meister, P.J. O'Dwyer, C.S. Huang, T.C. Hamilton, and M.E. Anderson. 1992. High resistance to cisplatin in human ovarian cancer cell lines is associated with marked increase of glutathione synthesis. Proc. Natl. Acad. Sci. USA. 89:3070-3074.

49. Andrews, P.A., M.P. Murphy, and S.B. Howell. 1987. Metallothioneinmediated cisplatin resistance in human ovarian carcinoma cells. Cancer Chemother. Pharmacol. 19:149-154.

50. Kelly, S.L., A. Basu, B.A. Teicher, M.P. Hacker, D.H. Hamer, and J.S. Lazo. 1988. Overexpression of metallothionein confers resistance to anticancer drugs. Science (Wash. DC). 241:1813-1815.

51. Iwata, S., T. Hori, N. Sato, Y. Ueda-Taniguchi, T. Yamabe, H. Nakamura, H. Masutani, and J. Yodoi. 1994. Thiol-mediated redox regulation of lymphocyte proliferation: possible involvement of adult $\mathrm{T}$ cell leukemiaderived factor and glutathione in transferrin receptor expression. J. Immunol. $152: 5633-5642$

52. Hori, K., M. Katayama, N. Sato, K. Ishii, S. Waga, and J. Yodoi. 1994. Neuroprotection by glial cells through adult $\mathrm{T}$ cell leukemia-derived factor/human thioredoxin (ADF/TRX). Brain Res. 652:304-310.

53. Sato, N., S. Iwata, K. Nakamura, T. Hori, K. Mori, and J. Yodoi. 1995. Thiol-mediated redox regulation of apoptosis: possible roles of cellular thiols other than glutathione in T cell apoptosis. J. Immunol. 154:3194-3203.

54. Smith, S.L., and K.T. Douglas. 1989. Stereoselective, strong inhibition of ribonucleotide reductase from E. coli by cisplatin. Biochem. Biophys. Res.
Commun. 162:715-723.

55. Chiu, C.S.M., A.K. Chan, and J.A. Wright. 1992. Inhibition of mammalian ribonucleotide reductase by cis-diamminedichloroplatinum(II). Biochem. Cell Biol. 70:1332-1338.

56. Mcclarty, G.A., A.K.M. Chan, and J.A. Wright. 1986. Hydroxyureainduced conversion of mammalian ribonucleotide reductase to a form hypersensitive to bleomycin. Cancer Res. 46:4516-4521.

57. Hurta, R.A.R., and J.A. Wright. 1992. Alterations in the activity and regulation of mammalian ribonucleotide reductase by chlorambucil, a DNA damaging agent. J. Biol. Chem. 267:7066-7071.

58. Wells, W.W., P.A. Rocque, D.-P. Xu, Y. Yang, and T.L. Deits. 1991. Interaction of platinum complexes with thioltransferase (glutaredoxin), in vitro. Biochem. Biophys. Res. Commun. 180:735-741.

59. Björnstedt, M., M. Hamberg, S. Kumar, J. Xue, and A. Holmgren. 1995. Human thioredoxin reductase directly reduces lipid hydroperoxides by NADPH and selenocystine strongly stimulates the reaction via catalytically generated selenols. J. Biol. Chem. 270:11761-11764.

60. Björnstedt, M., J. Xue, W. Huang, B. Akesson, and A. Holmgren. 1994. The thioredoxin and glutaredoxin systems are efficient electron donors to human plasma glutathione peroxidase. J. Biol. Chem. 269:29382-29384.

61. Arnér, E.S.J., M. Björnstedt, and A. Holmgren. 1995. 1-Chloro-2, 4-dinitrobenzene is an irreversible inhibitor of human thioredoxin reductase: loss of thioredoxin disulfide reductase activity is accompanied by a large increase in NADPH oxidase activity. J. Biol. Chem. 270:3479-3482.

62. Toyokuni, S., K. Okamoto, J. Yodoi, and H. Hiai. 1995. Persistent oxidative stress in cancer. FEBS Lett. 358:1-3. 